\title{
Balanced scorecard para micro e pequenas empresas: opinião de especialistas
}

No decorrer da evolução tecnológica dos meios de produção e serviços, indicadores sempre foram utilizados, da forma mais intuitiva à forma mais elaborada, no sentido de transmitir informações e respaldar decisões. Entretanto, essa não é a realidade de uma parte significativa das Micro e Pequenas Empresas no Brasil, uma vez que várias pesquisas evidenciam que seus gestores possuem dificuldades em traçar estratégias, gerar dados e implementar sistemas de informação de apoio a decisão. Diante dessa realidade e esperando contribuir para esse segmento empresarial, a presente pesquisa tem por objetivo selecionar indicadores de desempenho de fácil compreensão e utilização para este tipo de organização, com base em indicadores já existentes, sejam eles financeiros ou não financeiros, de forma que se obtenha um conjunto de indicadores apropriado para micro e pequenas empresas. Metodologicamente, esse trabalho é suportado por entrevistas junto a especialistas sobre o tema, utilizando-se o Método Delphi. Como resultado, obteve-se um conjunto de onze indicadores que abordam as perspectivas do Balanced Scorecard.

Palavras-chave: Indicadores de Desempenho; Balanced Scorecard; Micro e Pequenas Empresas; Método Delphi.

\section{Balanced scorecard for micro and small businesses: expert opinion}

In the course of the technological evolution of the means of production and services, indicators have always been used, in the most intuitive way to the most elaborate way, in the sense of transmitting information and supporting decisions. However, this is not the reality of a significant part of Micro and Small Companies in Brazil, since several surveys show that their managers have difficulties in devising strategies, generating data and implementing decision support information systems. Faced with this reality and hoping to contribute to this business segment, the present research aims to select performance indicators that are easy to understand and use for this type of organization, based on existing indicators, whether financial or non-financial, in order to get an appropriate set of indicators for micro and small businesses. Methodologically, this work is supported by interviews with specialists on the subject, using the Delphi Method. As a result, we obtained a set of eleven indicators that address the perspectives of the Balanced Scorecard.

Keywords: Performance indicators; Balanced Scorecard; Micro and Small Enterprises; Delphi method.

\section{Topic: Planejamento, Estratégia e Competitividade}

Reviewed anonymously in the process of blind peer.

\section{Vivian Magalhães Rodrigues}

Universidade Federal Fluminense, Brasil

http://lattes.cnpq.br/2610978545590766

vivi magarodri@hotmail.com

Ualison Rebula de Oliveira

Universidade Estadual Paulista Júlio de Mesquita Filho, Brasil http://lattes.cnpq.br/6460931837390456

ualison.oliveira@gmail.com
Received: 10/06/2016

Approved: 20/11/2016
Referencing this:

RODRIGUES, V. M.; OLIVEIRA, U. R.. Balanced scorecard para micro e pequenas empresas: opinião de especialistas. Revista Brasileira de Administração Científica, v.7, n.3, p.98-110, 2016. DOI: http://doi.org/10.6008/SPC2179-684X.2016.002.0007 


\section{INTRODUÇÃO}

No mundo empresarial, o gerenciamento de uma organização exige a elaboração de informações para respaldar as decisões (WONG, 2005). Assim, se faz necessário estabelecer parâmetros para a produção de informação e facilitar seu fluxo para o público interessado. Se existirem estes parâmetros formalizados na organização, a tomada de decisão é bem embasada e permite a identificação eficaz do problema; um dos fatores determinantes para o sucesso da empresa (BARROS FILHO e TUBINO, 1999).

Para Rocha e Oliveira (2006), as empresas com maior chance de sucesso serão aquelas com maior capacidade de reação, maior capacidade de lançar novos bens e serviços com rapidez e atender demandas e conquistar confiabilidade. Hoque (2014) defende que métodos de monitoramento e indicadores de desempenho eficientes devem estar alinhados com os objetivos estratégicos, visão e missão da organização, de forma que orientem a tomada de decisão.

$\mathrm{Na}$ administração de negócios, a abordagem matemática trouxe vários instrumentos e ferramentas de mensuração. O balanço contábil e as demonstrações financeiras são as medidas mais utilizadas nas organizações, porém apresentam restrições, ao se voltarem apenas para os ativos tangíveis ou como basearse na extrapolação de dados históricos passados (ROCHA e OLIVEIRA, 2006).

Na busca de um sistema de indicadores de desempenho que permitisse às empresas uma orientação correta, Kaplan e Norton (1997) apresentaram o Balanced Scorecard (BSC), ferramenta que "pressupõe que focos em diferentes agentes sejam analisados (dimensões) e possam direcionar objetivos, indicadores, metas e planos de ação de maneira coordenada" (FREZATTI et al., 2014). Ou seja, é um sistema de gestão que permite exprimir a estratégia da empresa em medidas de desempenho, permitindo que a estratégia passe a fazer parte da gestão do dia a dia da empresa, ampliando a visão para além do orçamento anual e introduzindo nos instrumentos de gestão a perspectiva de resultados presentes e o seu impacto futuro.

Os métodos desenvolvidos sobre a elaboração do Balanced Scorecard utilizam, em sua maioria, as grandes empresas como modelos dos seus relatos de aplicações práticas e teóricas, e conforme Kaplan e Norton (1997), o sistema deve refletir a estrutura da organização para qual a estratégia foi formulada. Porém, percebe-se que, em empresas de pequeno porte, existe a dificuldade de seguir rigidamente os passos propostos pelos precursores, surgindo a necessidade da elaboração de uma proposta que leve em consideração as características e recursos disponíveis pertinentes às pequenas empresas (PONGELLUPE e BATALHA, 2001).

Motivado por essa lacuna, a presente pesquisa possui por objetivo principal pesquisar, analisar e selecionar indicadores de desempenho que sejam de fácil utilização e compreensão para os micro e pequenos empresários. Metodologicamente, esse estudo é embasado na percepção de especialistas sobre o tema BSC, por meio da utilização do Método Delphi de pesquisa.

\section{REVISÃO TEÓRICA}

\section{Indicadores de Desempenho}


De acordo com Resnik (1991), a boa administração é determinante para a sobrevivência e sucesso de uma empresa. A boa administração é entendida como a capacidade de entender, dirigir e controlar a empresa baseada na atenção crítica do responsável pela administração aos fatores decisivos responsáveis pelo sucesso e sobrevivência da organização.

Esta "atenção crítica" para tomadas de decisões advém dos indicadores de desempenho que, conforme FNQ (2007), "são dados ou informações numéricas que quantificam as entradas (recursos ou insumos), saídas (produtos) e o desempenho de processos, produtos e da organização como um todo. Os indicadores são utilizados para acompanhar e melhorar os resultados ao longo do tempo." Assim, o indicador permite a obtenção de informação sobre dada realidade, podendo sintetizá-las e reter apenas o essencial do aspecto analisado para que fenômenos complexos quantitativos se tornem compreensíveis (CAMPOS E MELO, 2008).

Ferreira et al (2008) destacam que os indicadores de desempenho apontam à organização quais são seus vetores de sucesso atuais e futuros, para que os administradores possam canalizar energias, conhecimentos e habilidades dos colaboradores para alcançar as metas de longo prazo. Pace et al (2003) afirmam que um bom administrador controla o desempenho dos sistemas sob sua responsabilidade com o auxílio de indicadores, ocorrendo combinação de fatores que levam a tomada de decisão e o destino da organização.

Em 1992, a Harvard Business Review publicou o artigo The Balanced Scorecard: Measures that Drive Performance (Balance Scorecard: Indicadores que Impulsionam o Desempenho), um estudo que apontou uma nova abordagem para a mensuração de desempenho organizacional descrevendo um novo sistema para a gestão estratégica através de estudo de um ano de duração com 12 companhias nos Estados Unidos da América (GUMBUS E LUSSIER, 2006).

O Balanced Scorecard foi criado para suprir a necessidade de organização da informação empresarial de modo dinâmico, holístico e coerente com suas necessidades e estratégias. De acordo com Soares (2001), esta ferramenta foi criada para desenvolver um novo grupo de medidas de desempenho, pois medidas financeiras estavam se tornando obsoletas - o que prejudicava a capacidade da organização em criar valor econômico futuro. Assim, além das medidas financeiras, outras também passaram a ser consideradas, como apontam os precursores desta ferramenta.

Nunes (2008), resume o sistema afirmando que o BSC "traduz a visão estratégica de uma empresa em objetivos e medidas tangíveis", baseado em quatro perspectivas diferentes que se complementam, que representam o equilíbrio entre indicadores externos e internos, formando um conjunto único e interdependente, com objetivos e indicadores inter-relacionados que formam um fluxo de causa e efeito, iniciando na perspectiva do aprendizado e crescimento, passando por processos internos, clientes e terminando na perspectiva financeira. Estas perspectivas representam os três principais stakeholders de cada organização (acionistas, clientes e empregados), assegurando que a visão holística da organização é usada para reflexão estratégica e sua implementação (FERNANDES E RAJA, 2006). 
Com esta ferramenta, os executivos avaliam se suas unidades de negócios geram valor para clientes atuais e futuros, como melhorar suas capacidades e investimentos internos e em pessoal, além de sistemas e procedimentos para alavancar seu desempenho no futuro (KAPLAN \& NORTON, 1997). Nunes (2008) apresenta um exemplo de mapa estratégico baseando em Kaplan e Norton (1997) e explica que a Figura 1 demonstra a relação de causa e efeito proposta pelos precursores do BSC, onde:

[...] se aumentar a capacitação dos funcionários então diminui o índice de defeitos (devoluções). Se diminuir o índice de devoluções então aumenta a satisfação dos clientes. Se aumentar a satisfação dos clientes então aumenta a participação de mercado. Se aumenta a participação de mercado então aumenta o volume de receita.

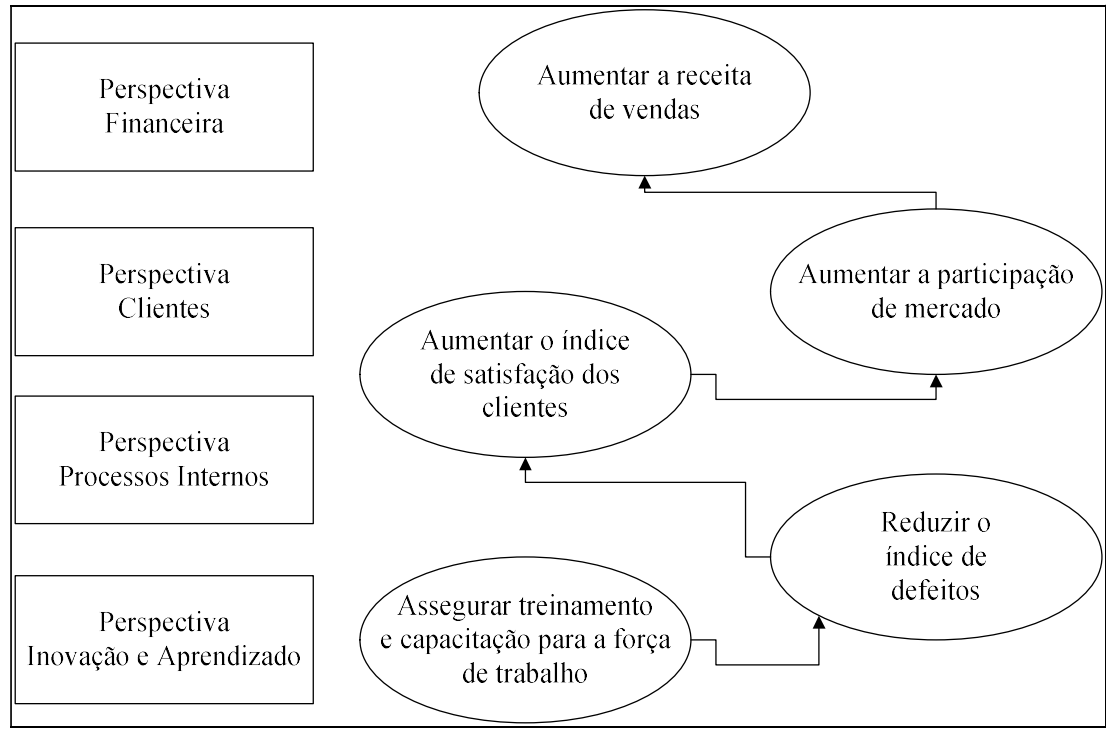

Figura 1: Exemplo de Mapa Estratégico. Fonte: Nunes (2008).

\section{Conceitos sobre Micro e Pequenas Empresas e Características de Gestão}

Almeida e Marçal (2008) afirmam que o aumento da competitividade estimula as empresas a buscarem inovações que objetivam o alcance da excelência. Como apresentado neste estudo, a excelência pode ser alcançada por meio do gerenciamento de desempenho - que significa criar visões para o futuro, planejar, criar estratégias, entre outras - para qualquer tipo de organização, inclusive para as Micro e Pequenas Empresas.

Focando neste tipo de organização, Nunes (2008) e Almeida (2005) concordam que existem diversos conceitos de MPE's que, geralmente, consideram critérios quantitativos (como número de empregados ou faturamento anual bruto), critérios qualitativos (como baixa especialização do pessoal ou dificuldades na obtenção de financiamentos) ou ambos. O IBGE (2001) aponta que a utilização de conceitos heterogêneos decorre do fato de que a finalidade e os objetivos das instituições que promovem seu enquadramento são distintos (regulamentação, crédito, estudos, etc.).

Nas MPE's, a estratégia é intuitiva e pouco formalizada, operando sob uma lógica de reação e adaptação ao ambiente, devido à ausência de planejamento formal (embora o gestor tenha uma visão estratégica não declarada); o que leva a característica seguinte: personalização da gestão na pessoa do proprietário-gestor, fato que o permite discutir com clientes para conhecer necessidades e gostos ou explicar especificidades de seu produto (BRAGUIER, 1993). 
Leone (1998) afirma que a tomada de decisão também é embasada no gestor dentro de uma ótica de curto prazo, já que ele não tem tempo nem habilidade necessária para uma postura mais analítica e estratégica. O sistema de valores do proprietário-gestor marca as tomadas de decisão e definição de políticas de sobrevivência, sendo sua empresa um prolongamento de si mesmo.

O perfil do gestor "é mais de um estrategista que corre riscos do que o de um administrador gestionário que procura aplicar uma estratégia minimizando riscos" (LEONE, 1998). Este fato ocorre devido a falta de dados necessários à análise para a tomada de decisão, sendo sua decisão um produto mais da racionalidade política e familiar do proprietário-gestor do que da racionalidade econômica.

Nos últimos anos, pesquisadores tentaram compreender problemas enfrentados por essas organizações por perceber seu papel na geração de novos empregos, impostos e sua importância social. Segundo a Coletânea Estatística da Micro e Pequena Empresa (SEBRAE, 2004), 99,2\% dos estabelecimentos comerciais no Brasil são classificados como MPE's e estes são responsáveis por 57,3\% dos empregos do país. Com este argumento, Almeida e Marçal (2008) destacam a incontestável importância das micro e pequenas empresas na economia no âmbito nacional; além da carência de estudos relacionados ao Planejamento, Implantação e Controle Estratégico nesse tipo de organização, corroborando com Leone (1998).

\section{METODOLOGIA}

Para a presente pesquisa, adotou-se o método de abordagem hipotético-dedutivo, por este partir pela percepção de uma lacuna nos conhecimentos, acerca da qual se formulam conjecturas e, pelo processo de inferência dedutiva, testa-se a predição da ocorrência de fenômenos abrangidos pelas conjecturas (MARCONI e LAKATOS, 2004). Após revisar os temas de indicadores de desempenho, Balanced Scorecard e MPEs, considerou-se possível elaborar conjecturas e utilizar dois caminhos (métodos) para corroborá-las ou refutá-las.

Primeiramente, optou-se por consultar professores doutores de uma universidade pública federal acerca dos indicadores de desempenho mais adequados para as MPE's. Nessa etapa, levou-se em consideração estudos desenvolvidos pelo SEBRAE sobre os fatores de insucesso em Micro e Pequenas Empresas. Os resultados encontrados nessa segunda etapa, segmentado nas quatro perspectivas do Balanced Scorecard, se constituíram no princípio do questionário elaborado para a consecução da seguinte etapa dessa pesquisa, servindo, também, como um teste piloto.

Dessa forma, a segunda etapa deste estudo consistiu na aplicação do método Delphi aos especialistas nacionais em BSC. Estes especialistas publicaram um artigo em periódicos nacionais (indexados no SCIELO) sobre o tema BSC. A finalidade desta etapa é obter consenso entre os entrevistados sobre um conjunto de indicadores de desempenho para MPEs, uma vez que o método Deplhi baseia-se no uso estruturado do conhecimento, da experiência e da criatividade dos respondentes, pressupondo-se que o julgamento coletivo, quando organizado adequadamente, é melhor que a opinião de um só indivíduo (OKOLI e PAWLOWSKI, 2004). Os participantes da pesquisa responderam os questionários em três rodadas, 
até que fosse estabelecido um consenso "técnico" entre os participantes.

\section{RESULTADOS}

A partir da coleta de dados de pesquisas realizadas pelo SEBRAE (2004), durante o desenvolvimento do referencial teórico, desenvolveu-se o Quadro 1, onde a primeira coluna elenca as principais razões de fechamento de MPE's, categorizando-as nas quatro perspectivas do BSC (segunda coluna).

Quadro 1: Razões para Fechamento de Micro e Pequenas Empresas categorizados nas perspectivas do BSC.

\begin{tabular}{|l|l|}
\hline Fatores SEBRAE & \multirow{2}{*}{ BSC } \\
\cline { 1 - 1 } Falta de Capital de Giro & \\
\cline { 1 - 1 } Baixo Lucro & \multirow{2}{*}{ Perspectiva FINANCEIRA } \\
\hline Dificuldade Financeira & \\
\hline Falta de Crédito & Perspectiva de PROCESSOS INTERNOS \\
\cline { 1 - 1 } Maus Pagadores & \\
\hline Concorrência & Perspectiva de APRENDIZADO E CRESCIMENTO \\
\cline { 1 - 1 } Burocracia & \\
\hline Falta de Clientes & \\
\hline Falta de Mão de Obra Qualificada &
\end{tabular}

Baseando-se nessas informações (Quadro 1), foram entrevistados quatro professores doutores de dedicação exclusiva de uma universidade pública federal, que lecionam e pesquisam nas áreas de Administração Financeira, Marketing, Administração da Produção e Gestão de Recursos Humanos. Nessa entrevista, cada professor sugeriu indicadores de desempenho que ajudassem a gerenciar os fatores que mais contribuem para o fechamento das MPE's (Quadro 2).

Quadro 2: Indicadores resultantes do cruzamento entre Razões para Fechamento da MPE do SEBRAE e BSC.

\begin{tabular}{|c|c|c|}
\hline Fatores SEBRAE & $\mathrm{BSC}$ & Indicadores \\
\hline Falta de Capital de Giro & \multirow{6}{*}{ Perspectiva FINANCEIRA } & Giro do Ativo \\
\hline Baixo Lucro & & Margem Líquida \\
\hline Dificuldade Financeira & & Rentabilidade do Ativo \\
\hline \multirow{3}{*}{ Falta de Crédito } & & Liquidez Seca \\
\hline & & Prazo Médio de Pagamento \\
\hline & & Prazo Médio de Recebimento \\
\hline \multirow{2}{*}{ Maus Pagadores } & \multirow{4}{*}{$\begin{array}{l}\text { Perspectiva dos CLIENTES E } \\
\text { MERCADO }\end{array}$} & Eficiência Mercadológica \\
\hline & & Taxa de Inadimplência \\
\hline \multirow{2}{*}{ Concorrência } & & Taxa de devolução \\
\hline & & Retenção de clientes \\
\hline Burocracia & \multirow{2}{*}{$\begin{array}{l}\text { Perspectiva de PROCESSOS } \\
\text { INTERNOS }\end{array}$} & $\%$ Falha no Atendimento \\
\hline Falta de Clientes & & Taxa de Retrabalho \\
\hline \multirow{2}{*}{$\begin{array}{l}\text { Falta de Mão de Obra } \\
\text { Qualificada }\end{array}$} & \multirow[b]{4}{*}{$\begin{array}{l}\text { Perspectiva de APRENDIZADO E } \\
\text { CRESCIMENTO }\end{array}$} & Taxa de contratação por currículo \\
\hline & & Tempo médio para preenchimento de vagas \\
\hline \multirow[b]{2}{*}{$\begin{array}{l}\text { Falta de Conhecimento da Área } \\
\text { de Gestão }\end{array}$} & & Taxa de Fruição da informação \\
\hline & & $\begin{array}{l}\text { Tempo médio (em anos) de educação formal por } \\
\text { trabalhador empregado }\end{array}$ \\
\hline
\end{tabular}

Com base no conhecimento prévio adquirido (Quadro 2), tanto pelo desenvolvimento do referencial teórico, quanto pelas entrevistas com os docentes, elaborou-se o arcabouço do questionário da primeira rodada da metodologia Delphi. Esse primeiro questionário foi assim desenvolvido (a partir do Quadro 2) com o intuito de reduzir o número de rodadas da Metodologia Delphi, uma vez que se partiu de um documento elaborado com base em conhecimento consolidado (fundamentação teórica) e percepção de profissionais 
que dominam as áreas de conhecimento relacionadas às quatro perspectivas do BSC. Em linhas gerais, o primeiro questionário perguntava ao respondente se determinado indicador seria apropriado para as Micro e Pequenas Empresas, solicitando que fosse respondido "SIM" ou "NÃO".

Além disso, todos os questionários foram elaborados seguindo as orientações de Wright e Giovinazzo (2000), as quais apontam que, ao elaborar questões, o autor deve evitar eventos compostos, evitar colocações ambíguas, tornar o questionário simples de ser respondido, esclarecer previsões contraditórias, evitar ordenamento de proposições e permitir complementações dos painelistas.

Para enviar o questionário, utilizou-se a ferramenta de questionário do "Google Drive", que é um facilitador no desenvolvimento do questionário e na tabulação das respostas. Este sistema cria um weblink com o conteúdo do questionário para ser enviado por e-mail aos painelistas. Assim, agilizou-se o processo de aplicação da pesquisa, cujas respostas foram organizadas por meio do Quadro 3.

Quadro 3: Resultados da Primeira Rodada da Pesquisa.

\begin{tabular}{|c|c|c|c|c|c|c|c|c|}
\hline & FINANCEIROS & $\%$ & $\begin{array}{l}\text { CLIENTES E } \\
\text { MERCADO }\end{array}$ & $\%$ & INTERNOS & $\%$ & $\begin{array}{l}\text { APRENDIZADO E } \\
\text { CRESCIMENTO }\end{array}$ & $\%$ \\
\hline \multirow{8}{*}{ 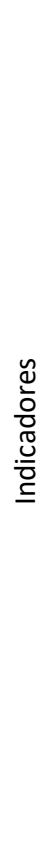 } & Giro do Ativo & 33 & $\begin{array}{l}\text { Margem de } \\
\text { Relevância no } \\
\text { Composto do } \\
\text { produto }\end{array}$ & 33 & $\begin{array}{c}\% \text { Falha no } \\
\text { Atendimento }\end{array}$ & 100 & $\begin{array}{c}\text { Tempo médio para } \\
\text { preenchimento de } \\
\text { vagas }\end{array}$ & 0 \\
\hline & Margem Líquida & 100 & $\begin{array}{c}\text { Eficiência } \\
\text { Mercadológica }\end{array}$ & 0 & $\begin{array}{c}\text { Acuracidade no } \\
\text { Estoque }\end{array}$ & 0 & $\begin{array}{l}\text { Investimento total } \\
\text { com remuneração }\end{array}$ & 33 \\
\hline & $\begin{array}{c}\text { Endividamento } \\
\text { Oneroso }\end{array}$ & 100 & $\begin{array}{c}\text { Taxa de } \\
\text { crescimento }\end{array}$ & 100 & Absenteísmo & 33 & Treinamento & 66,7 \\
\hline & Ciclo Operacional & 0 & $\begin{array}{c}\text { Taxa de } \\
\text { Inadimplência }\end{array}$ & 66,7 & $\begin{array}{c}\text { Taxa de } \\
\text { Retrabalho }\end{array}$ & 100 & Taxa de Autonomia & 33 \\
\hline & $\begin{array}{c}\text { Rentabilidade do } \\
\text { Ativo }\end{array}$ & 33 & $\begin{array}{c}\text { Taxa de } \\
\text { Devolução }\end{array}$ & 33 & & & $\begin{array}{l}\text { Taxa de Fruição da } \\
\text { Informação }\end{array}$ & 33 \\
\hline & Liquidez Seca & 33 & $\begin{array}{l}\text { Retenção de } \\
\text { Clientes }\end{array}$ & 100 & & & $\begin{array}{l}\text { Tempo Médio (em } \\
\text { anos) de educação } \\
\text { formal por } \\
\text { trabalhador } \\
\text { empregado }\end{array}$ & 33 \\
\hline & $\begin{array}{l}\text { Prazo Médio de } \\
\text { Pagamento }\end{array}$ & 66,7 & & & & & $\begin{array}{c}\text { Taxa de contratação } \\
\text { por currículo }\end{array}$ & 33 \\
\hline & $\begin{array}{l}\text { Prazo Médio de } \\
\text { Recebimento }\end{array}$ & 66,7 & & & & & & \\
\hline
\end{tabular}

Ao observar o Quadro 3, constata-se que todos os respondentes acreditam que os indicadores "Ciclo Operacional", "Eficiência Mercadológica", "Acuracidade no Estoque" e "Tempo Médio para Preenchimento de Vagas" não são bons indicadores para as MPE's, ou seja, houve consenso a respeito da exclusão desses indicadores do rol de indicadores recomendados para Micro e Pequenas Empresas.

Por outro lado, os entrevistados julgam que os indicadores Margem Líquida, Endividamento Oneroso, Taxa de Crescimento, Retenção de Clientes, Falha no Atendimento e Taxa de retrabalho são bons indicadores para as MPE's, com o devido consenso entre os respondentes para a inclusão desses indicadores no rol de indicadores de desempenho recomendados para as Micro e Pequenas Empresas.

Quanto aos indicadores que não foram alvo de consenso, partiu-se para uma segunda rodada, com a aplicação de um novo questionário. Durante o segundo questionário, houve uma interação com feedback 
controlado junto aos respondentes, onde estatísticas sobre as respostas do grupo foram apresentadas para mostrar padrões de "de acordo" entre os participantes, visando estimular a reflexão dos painelistas sobre suas respostas. Além disso, nesse segundo questionário, incluiu-se três novos indicadores, que foram sugeridos pelos próprios participantes durante a primeira rodada. O Quadro 4 mostra esses indicadores, já categorizados segundo as perspectivas do BSC.

Quadro 4: Novos indicadores sugeridos pelos painelistas durante a primeira rodada de entrevistas.

\begin{tabular}{|l|l|}
\hline PERSPECTIVA DO BSC & INDICADORES \\
\hline Financeira & Rentabilidade sobre o Patrimônio Líquido = Lucro Líquido / Patrimônio Líquido \\
\hline Inovação e Aprendizado & Taxa de Rotatividade = (Entrada + Saída/ 2)/ Total de Funcionários \\
\hline Processos Internos & $\%$ de Informatização= \% de Informatização das Atividades / Total das Atividades \\
\hline
\end{tabular}

Na coleta de dados do segundo questionário, observou-se que os indicadores: i) Prazo Médio de Pagamento; ii) Prazo Médio de Recebimento; iii) Taxa de Inadimplência e; iv) Treinamento, que na primeira rodada foram alvos de desacordos entre os especialistas, agora, após consenso entre eles, devem ser adicionados ao rol de indicadores para as Micro e Pequenas Empresas. Além desses, o indicador "\% de Informatização", que foi incluído na segunda etapa, como sugestão de um dos especialistas, também, deve fazer parte do referido rol. Assim, obtém-se como resultado final o Quadro 5, que agrega onze indicadores de desempenho para as MPE's.

Quadro 5: Conjunto de Indicadores de Desempenho mais apropriados para as Micro e Pequenas Empresas

\begin{tabular}{|c|c|c|c|c|}
\hline PERSPECTIVA DO BSC & \multicolumn{4}{|l|}{ INDICADORES } \\
\hline Financeira & $\begin{array}{l}\text { Margem } \\
\text { Líquida }\end{array}$ & $\begin{array}{c}\text { Endividamento } \\
\text { Oneroso }\end{array}$ & $\begin{array}{r}\text { Prazc } \\
\text { Pa }\end{array}$ & $\begin{array}{l}\text { Prazo Médio de } \\
\text { Recebimento }\end{array}$ \\
\hline Clientes e Mercado & Taxa de crescimento & \multicolumn{2}{|c|}{ Taxa de crescimento } & Taxa de crescimento \\
\hline Processos Internos & $\%$ Falha no Atendimento & \multicolumn{2}{|c|}{ Taxa de Retrabalho } & \% de Informatização \\
\hline $\begin{array}{c}\text { Inovação e } \\
\text { Aprendizado }\end{array}$ & \multicolumn{4}{|c|}{ Treinamento } \\
\hline
\end{tabular}

\section{DISCUSSÃO}

Como apontado no início deste trabalho, a elaboração de um conjunto de indicadores de desempenho que permita à organização uma orientação correta é essencial para o sucesso de qualquer tipo de organização. Diversos modelos, como apresentados no embasamento teórico deste estudo, foram criados visando esta "orientação correta". Porém, estes modelos apontam ampla gama de indicadores que devem ser escolhidos pelas organizações, de acordo com suas necessidades, para melhor satisfazê-las.

Neste sentido, ao analisar a realidade das Micro e Pequenas Empresas, percebe-se que existem muitos indicadores que não tem utilidade ou não há interesse, por parte do micro gestor, em investir tempo e recursos no levantamento de índices, por mais essenciais que estes demonstrem ser. Esta elucidação pode ser embasada na afirmação de Leone (1998), "para o dirigente, é preferível agir só e guiado mais pela sua sensibilidade do que pelos meios técnicos de administração fornecidos pela Ciência às empresas dotadas de uma organização administrativa sofisticada".

Além disso, em muitos casos a inexistência de dados ou dados incorretos podem levar às micro e pequenas organizações ao levantamento de índices errôneos (LEONE, 1998), e invalidando o real objetivo destes: orientação correta. 
Por outro lado, a falta de "orientação correta", a estratégia intuitiva e o baixo nível de planejamento se apresentam como alguns dos fatores de insucesso das MPE's. Neste sentido, o uso de indicadores selecionados pode ser pensado numa forma de introduzir a prática do planejamento e estratégia neste tipo de organização tão importante.

O método delphi permitiu que especialistas em Balanced Scorecard opinassem sobre esta questão, resultando em um conjunto de indicadores de desempenho genérico para as Micro e Pequenas Empresas. $O$ Quadro 6 apresenta os resultados desses indicadores de forma detalhada, mostrando a base de cálculo de cada indicador.

Quadro 6: Indicadores de Desempenho mais apropriados para as Micro e Pequenas Empresas.

\begin{tabular}{|c|c|c|c|c|}
\hline & FINANCEIROS & CLIENTES E MERCADO & INTERNOS & $\begin{array}{l}\text { APRENDIZADO E } \\
\text { CRESCIMENTO }\end{array}$ \\
\hline \multirow{3}{*}{ 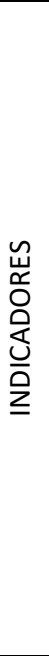 } & $\begin{array}{c}\text { Endividamento } \\
\text { Oneroso } \\
\text { Empréstimos / Passivo } \\
\text { Circulante }\end{array}$ & $\begin{array}{l}\text { Taxa de crescimento (Volume } \\
\text { de Vendas Tn - Volume de } \\
\text { Vendas Tn- } 1 \text { ) / Volume de } \\
\text { Vendas no período }\end{array}$ & $\begin{array}{c}\text { Taxa de Retrabalho } \\
\text { Retrabalho / produção } \\
\text { total }\end{array}$ & $\begin{array}{l}\text { \% de Informatização } \\
\% \text { de Informatização } \\
\text { das Atividades / } \\
\text { Total de Atividades }\end{array}$ \\
\hline & $\begin{array}{c}\text { Prazo Médio de } \\
\text { Pagamento } \\
\text { (Fornecedores Médio / } \\
\text { Custo da Mercadoria } \\
\text { Vendida) x } 360 \\
\end{array}$ & $\begin{array}{c}\text { Taxa de Inadimplência } \\
\text { Contas a Receber em Atraso / } \\
\text { Contas a Receber }\end{array}$ & \multirow{2}{*}{$\begin{array}{l}\text { \% Falha no Atendimento } \\
\text { Clientes não atendidos por } \\
\text { falta de produto ou } \\
\text { transporte / total de } \\
\text { clientes atendidos }\end{array}$} & \multirow{2}{*}{$\begin{array}{c}\text { Treinamento } \\
\text { Tempo (em horas) Investidas } \\
\text { em treinamento por mês / } \\
\text { total de horas trabalhadas } \\
\text { por mês }\end{array}$} \\
\hline & $\begin{array}{c}\text { Prazo Médio de } \\
\text { Recebimento } \\
\text { (Contas a receber / } \\
\text { vendas líquidas) x } 360\end{array}$ & $\begin{array}{c}\text { Retenção de Clientes } \\
\text { Quantidade de clientes ano } \\
\mathrm{n}+1 \text { / quantidade clientes ano } \\
\mathrm{n}\end{array}$ & & \\
\hline
\end{tabular}

Kaplan e Norton (1997) afirmam que a perspectiva financeira é foco para os objetivos das outras perspectivas, de forma que todas as medidas devem resultar na melhoria do desempenho financeiro. Esta perspectiva apresenta o desempenho financeiro da organização e é a principal meta dos objetivos e medidas das demais perspectivas.

Neste sentindo, o primeiro indicador do conjunto desenvolvido é "Margem Líquida". Matarazzo (2010) afirma que este indicador de rentabilidade aponta quanto à empresa obtém de lucro para cada cem unidades monetárias vendidas, medindo a eficiência global da organização. Assim, em uma visão generalizada, as empresas que são mais lucrativas possuem margem líquida maiores, porém não se pode deixar de analisá-la em um contexto maior, comparando com a concorrência e analisando fatores externos. Este índice pode ser relacionado com o item "Baixo Lucro" e "Dificuldade Financeira" das razões para fechamento das MPE's e indicar para o gestor a rentabilidade de sua empresa.

O segundo indicador financeiro, "Endividamento Oneroso", mede o percentual de comprometimento do capital próprio da empresa em relação à dívida financeira, ou seja, mensura a participação do endividamento que gera despesa financeira para empresa em relação ao total do ativo (MATARAZZO, 2010).

O terceiro índice financeiro é "Prazo Médio de Pagamento", que indica o número de dias que a empresa leva para pagar os fornecedores. Este índice aponta a quantidade de tempo que a empresa é 
financiada pelo principal passivo não oneroso (fornecedores). Matarazzo (2010) afirma que valores baixos podem indicar que a empresa não é capaz de obter prazo dos fornecedores para financiar seus ativos; já valores muito elevados podem indicar dificuldade em efetuar pagamentos. Assim, é importante analisar características do setor e sazonalidade.

O quarto e último índice financeiro é o "Prazo Médio de Recebimento", que revela quantos dias a empresa espera para receber as vendas (tempo decorrido entre a data da venda e a de seu recebimento), no qual o ideal é receber as duplicatas das vendas, antes de pagar as duplicatas das compras.

Kaplan e Norton (1997) afirmam que para melhorar o desempenho financeiro a longo prazo, as organizações precisam desenvolver produtos e serviços valorizados pelos clientes. Neste sentido, a perspectiva dos clientes e mercado alinha as medidas de resultados aos clientes (satisfação, fidelidade, retenção, captação, lucratividade).

Para esta perspectiva, o primeiro índice do Quadro é a "Taxa de Crescimento". Esta taxa aponta o aumento das vendas da organização, que traduz o crescimento da demanda por parte do mercado e reflete no crescimento da organização, aumento do arranjo produtivo ou de colaboradores, por exemplo. 0 crescimento nas vendas pode traduzir a satisfação ou insatisfação do cliente se analisado historicamente, por exemplo. É um índice de fácil mensuração e importante para a decisão de expansão ou continuidade na elaboração de determinado produto ou serviço.

O segundo índice da perspectiva de clientes e mercado é o cálculo da "Taxa de Inadimplência". Este índice mostrará ao gestor o nível de inadimplência de seus clientes, o que pode auxiliá-lo na decisão sobre concessão de crédito e na ação sobre suas políticas de cobrança. Gerenciar a concessão de crédito e, com isso, o risco implícito é essencial para aumentar as vendas, manter políticas de crédito eficazes, garantir o recebimento, manter o fluxo de caixa previsível e confiável e reduzir custos na liberação e recuperação de crédito (SEBRAE, 2004).

O terceiro e último índice desta perspectiva é "Retenção de Clientes", que aponta a variação da quantidade de clientes no ano, e é importante para o gestor verificar se há aumento, redução ou estabilidade de clientes no decorrer do período. Ao verificar o resultado deste índice, o gestor pode decidir se está satisfeito e manter suas atividades; pode decidir se deseja ampliar a quantidade de clientes através de atividades de marketing e expansão da produção ou então decidir reduzir a quantidade de clientes através de aumento de preço ou redução de crédito.

No tocante a realização das expectativas dos clientes e do mercado, os processos internos devem estar alinhados com a estratégia da organização, por meio de uma cadeia de valor completa dos processos internos. Esta cadeia é observada na perspectiva interna do BSC, na qual os executivos podem visualizar processos cruciais para realizar os objetivos dos clientes e acionistas. Para o micro e pequeno empresário, esses indicadores visam estimular o pensamento crítico do gestor no que tange o planejamento interno. 0 primeiro indicador nessa perspectiva é a "Taxa de Retrabalho", que apontará ao gestor o nível de erro no processo, o quanto houve de desperdício, ou seja, falhas no processo produtivo que geram ônus à organização. Este indicador pode estimular o gestor e seus colaboradores a pensar e implementar formas de 
otimizar um processo.

Esta interpretação também é válida para o segundo índice selecionado - "\% de Falha no Atendimento", que pode apontar falhas na produção ou no processo de vendas da empresa, estimulando o gestor a buscar a otimização do processo ou o treinamento do vendedor, por exemplo. Para que os indicadores de processos internos estejam em um patamar aceitável, é essencial o investimento em aprendizado e crescimento - a quarta perspectiva do BSC. Kaplan e Norton (1997) apontam que este tipo de investimento é essencial para o desempenho excelente das organizações no longo prazo, sendo necessário investir tanto em treinamento e pesquisa quanto em infraestrutura.

O primeiro indicador dessa perspectiva sugerido pelos painelistas é o "\% de Informatização", que mostra ao gestor, dentre todas as atividades realizadas pela organização, a quantidade de informatização destas atividades. Este índice é importante para auxiliar o gestor a buscar alternativas que automatizem seus processos, tanto de produção quanto administrativos na perspectiva de obter infraestrutura adequada.

O segundo indicador desta perspectiva é o "Treinamento", que aponta a relação entre horas investidas e horas trabalhadas no mês. Este indicador está diretamente relacionado aos resultados internos da organização, já que com profissionais treinados, os processos são executados com mais qualidade, e consequentemente, melhores resultados financeiros. Com este último indicador, pode-se ver claramente a conexão existente entre as quatro perspectivas do BSC, como cada perspectiva contribui para a realização da outra.

Finalizando essa seção, chama-se a atenção para a afirmação de Rocha e Oliveira (2006), que afirmam que cada empresa possui características peculiares e que, por isso, cada uma demandará um rol de indicadores apropriados para seu negócio. Indo ao encontro dessa afirmação, o conjunto de indicadores levantados apresentados no Quadro 8 não é único e nem imutável para todas as Micro e Pequenas Empresas. Entretanto, tem como propósito servir como um conjunto de indicadores introdutório para Micro e Pequenas Empresas que ainda não aderiram à prática de medição de desempenho para a "orientação correta" de seu negócio.

\section{CONCLUSÕES}

Este estudo apresentou um conjunto de indicadores calçado nas perspectivas do BSC para as Micro e Pequenas Empresas, concretizando o objetivo principal desta pesquisa. Para alcançar este objetivo principal, apresentou-se uma revisão teórica sobre indicadores de desempenho, MPE's e sobre o método Delphi; posteriormente, realizou-se uma pesquisa sobre indicadores de desempenho com professores doutores de dedicação exclusiva de uma Universidade Federal para, em seguida, consultar especialistas da área de indicadores de desempenho utilizando o método Delphi.

A partir da análise dos resultados, discutiu-se que a não utilização dos indicadores de desempenho pelas MPE's ocorre devido a sua estratégia intuitiva e ao baixo nível de planejamento, mas que a necessidade de uma "orientação correta" faz com que a utilização de um conjunto de indicadores seja indispensável para o pequeno gestor. 
$\mathrm{Na}$ análise dos resultados, discutiu-se o resultado principal, ou seja, os onze indicadores apontados pelos especialistas segmentados nas quatro perspectivas do Balanced Scorecard. Na primeira perspectiva, financeira, foram elencados quatro indicadores: (1) margem líquida; (2) endividamento oneroso; (3) prazo médio de pagamento; (4) prazo médio de recebimento. Na segunda perspectiva, de clientes e mercado, foram apontados três indicadores: (1) taxa de crescimento; (2) taxa de inadimplência; (3) retenção de clientes. Na terceira perspectiva, de processos internos, foram levantados dois indicadores: (1) taxa de retrabalho; (2) \% falha no atendimento. E na quarta e última perspectiva, de aprendizado e crescimento, foram elencados dois indicadores: (1) \% de informatização e (2) treinamento. Estes indicadores é resultado do método de pesquisa adotado neste estudo e são apresentados detalhadamente na discussão dos resultados.

Destacou-se, portanto, que o resultado alcançado na presente pesquisa não é um modelo generalizado para todas Micro e Pequenas Empresas, pois cada empresa tem o seu sistema de indicador próprio. Entretanto, o resultado alcançado convém para que uma MPE, sem um sistema de indicadores depurado e próprio para o seu empreendimento, possa iniciar as medições de seu negócio com base no sistema de indicadores de desempenho para MPE's aqui desenvolvido.

Pode-se concluir que as conjecturas apresentadas foram confirmadas uma vez que: (i) o levantamento bibliográfico confirmou que as MPE's apresentam baixa utilização de indicadores de desempenho; (ii) os indicadores de desempenho relacionados a aprendizado e crescimento os menos relevantes para uma MPE, pelo menos no sentido quantitativo, uma vez que o resultado apresenta apenas dois indicadores relacionados as esta perspectiva; (iii) os indicadores de desempenho relacionados à gestão financeira são os mais representativos não só para uma MPE, mas para qualquer tipo de organização, uma vez que são o foco para as outras perspectivas; e (iv) confirma-se também na discussão dos resultados que os indicadores de desempenho relacionados aos processos internos sugerem ao gestor formas de aperfeiçoar processos.

Como apontado no método de pesquisa deste estudo, apenas pesquisadores nacionais foram incluídos por considerar que o ambiente brasileiro tem peculiaridades que estes não desconsiderariam. Entretanto, considera-se válido, em futura pesquisa, buscar refutar (ou não) a premissa de que as peculiaridades do ambiente brasileiro sugerem o uso de indicadores diferentes de MPE's estrangeiras. Dessa forma, sugere-se para futuros estudos a aplicação da metodologia Delphi Conferencing (TUROFF, 1972) com especialistas em Balanced Scorecard e Micro e Pequenas Empresas em âmbito internacional.

Portanto, pode-se afirmar que os objetivos foram atingidos e que este estudo pode contribuir para a comunidade acadêmica como uma estruturada revisão bibliográfica e um estudo mais aprofundado sobre a medição de desempenho para as MPE's; contribui, também, para a sociedade empresarial, ao apresentar modelos e tipos de indicadores de desempenho para diversos e diferentes objetivos, além de um conjunto de indicadores de desempenho introdutório para as micro e pequenas organizações, que ainda não realizam esta prática empresarial. 


\section{REFERÊNCIAS}

ALMEIDA, S.. Adequação De Técnicas E Ferramentas Para A Gestão Estratégica Em Micros E Pequenas Empresas: uma proposta. Dissertação (Mestrado em Administração) Universidade Tecnológica Federal do Paraná, Ponta Grossa, 2005.

ALMEIDA, S.; MARÇAL, R. F. M.. Técnicas e Ferramentas para a Gestão Estratégica nas Micros e Pequenas Empresas: Uma Proposta. Simpósio de Engenharia de Produção, 13. Anais. Bauru: 2006.

BARROS FILHO, J. R.; TUBINO, D. F.. Implantação do planejamento e controle da produção em pequenas e médias empresas. ENCONTRO NACIONAL DE ENGENHARIA DE PRODUÇÃO, 19. Anais. Natal: 1999.

BRAGUIER, I.. Le comportement organisationnel et strategique dês PME: l'effet de l'incertitude perçe de l'environnement. Université de Poitiers, IAE, 1993.

CAMPOS, L.M. S.; MELO, D. A.. Indicadores de desempenho dos Sistemas de Gestão Ambiental (SGA): uma pesquisa teórica. Produção, v.18, n.3, p.540-555, 2008.

FERNANDES, K. J.; RAJA, V.; W., A.. Lessons from implementing the balanced scorecard in a small and medium size manufacturing organization. Technovation, v.26, p.623634, 2006.

FERREIRA, M. P.; ABREU, A. F.; ABREU; P. F.; TRZECIAK. D. S.; APOLINÁRIO, L. G.; CUNHA, A. A.. Gestão por indicadores de desempenho: resultados na incubadora empresarial tecnológica. Produção, v.18, n.2, p.302-318, 2008.

FNQ. Rumo à excelência e compromisso com a excelência. São Paulo: Fundação Nacional da Qualidade, 2007.

FREZATTI, F; BIDO, D. S.; CRUZ, A. P. C.; MACHADO, M. J. C.. O Papel do Balanced Scorecard na Gestão da Inovação. RAE, v.54, n.4, p.381-392, 2014.

GUMBUS, A.; LUSSIER, R. N.. Entrepreneurs Use a Balanced Scorecard to Translate Strategy into Performance Measures. Journal of Small Business Management, v.44, n.3, p.407425, 2006.

HOQUE, Z.. 20 years of studies on the balanced scorecard: Trends, accomplishments, gaps and opportunities for future research. The British Accounting Review, v.46, p.33-59, 2014.

IBGE. Instituto Brasileiro de Geografia e Estatística. As Micro e Pequenas Empresas Comerciais e de Serviço no Brasil. Estudos e Pesquisas: Informação Econômica, v.1, 2001.

KAPLAN, R. S., NORTON, D. P.. A estratégia em ação: Balanced Scorecard. 13 ed. Rio de Janeiro: Campus, 1997.
LEONE, N. M. C. P. G.. As especificidades das pequenas e médias empresas. Revista de Administração, v.34, n.2, p.9194, 1998.

MARCONI, M. A.; LAKATOS, E. M.. Metodologia Científica. 6 ed. São Paulo: Atlas, 2004.

MATARAZZO, D. C.. Análise Financeira de Balanços: abordagem gerencial. 7 ed. São Paulo: Atlas, 2010.

NUNES, A. V.. Indicadores de desempenho para as micro e pequenas empresas: uma pesquisa com as MPE's associadas a microempa de Caxias do Sul/RS. Dissertação (Mestrado em Administração) - Universidade de Caxias do Sul, Caxias do Sul, 2008

OKOLI, C.; PAWLOWSKI, S. D.. The Delphi method as a research tool: an example, design considerations and applications. Informatione Management, v.42, p.15-29, 2004.

PACE, E. S. U.; BASSO, L. F. C.; SILVA, M. A.. Indicadores de desempenho como direcionadores de valor. Revista Administração Contemporânea, v.7, n.1, p.37-65, 2003.

PONGELUPPE, P. C.; BATALHA, M. O.. Utilização de Indicadores de Desempenho para Micro e Pequenas Empresas. ENCONTRO NACIONAL DE ENGENHARIA DE PRODUÇÃO, 21. Anais. Salvador, 2001.

RESNIK, P.. A bíblia da pequena e média empresa. São Paulo: Makron Books, 1991.

ROCHA, H. M.; OLIVEIRA, U. R.. Balanced Scorecard como fonte de vantagem competitiva para as organizações: uma revisão bibliográfica. In: SIMPÓSIO DE ENGENHARIA DE PRODUÇÃO, 3. Anais. Bauru, 2006.

SEBRAE. Serviço Brasileiro de Apoio às Micro e Pequenas Empresas. Fatores condicionantes e taxa de mortalidade de empresas no Brasil. Brasília: SEBRAE, 2004.

SOARES, C. R. D.. Desenvolvimento de uma sistemática de elaboração de Balanced Scorecard para pequenas empresas. Dissertação (Mestrado em Administração) Universidade Federal Rio Grande do Sul, Porto Alegre, 2001.

TUROFF, M.. Delphi Conferencing: Computer-Based Conferencing with Anonymity. Technological Forecasting and Social Change, v.3, p.159-204, 1972.

WONG, K. Y.. Critical success factors for implementing knowledge management in small and medium enterprises. Industrial Management \& Data Systems, n.105, p.261-279, 2005.

WRIGHT, J. T. C.; GIOVINAZZO, R. A.. Delphi: Uma Ferramenta de Apoio ao Planejamento Prospectivo. Caderno de Pesquisas em Administração, v.1, n.12, 2000. 